\title{
Prevalence of human Salmonellosis in Ethiopia: a systematic review and meta-analysis
}

\author{
Getachew Tadesse
}

\begin{abstract}
Background: Human Salmonellosis is one of the major diseases in Ethiopia and several factors including under and mal-nutrition and HIV-AIDS may substantially contribute to its occurrence. Despite its importance, surveillance and monitoring systems are not in place and a comprehensive picture of its epidemiology is not available. The objectives of this study were to systematically review and estimate the prevalence of the disease and identify the dominant serogroups and serotypes in Ethiopia.

Methods: Published studies on Salmonellosis in Ethiopia were electronically and manually searched. Eligible studies were selected by using inclusion and exclusion criteria. Generic, methodological and statistical information were extracted from the eligible studies. The extracted data included sample sizes, the numbers of Salmonella positive samples, serogroups and serotypes. The variations in prevalence estimates attributable to heterogeneities were assessed and pooled prevalence was estimated by the random effects model.

Results: Twenty studies carried out between 1974 and 2012 were eligible. The pooled prevalence estimates of Salmonella in stool samples of diarrheic children, diarrheic adults and carriers were 8.72\%, 5.68\%, and 1.08\% respectively. Invasive infections in children (5.71\%) and adults $(0.76 \%)$ were significantly different $(p<0.001)$. Non-typhi isolates accounted for $57.9 \%$ of the isolates from patients. Serogroup D occurred more frequently than serogroups C and B. S. Concord, S. Typhi, S. Typhimurium and S. Paratyphi were dominant and accounted for $82.1 \%$ of the serotypes isolated from patients.

Conclusion: The prevalence of Salmonellosis is considerable and most infections are due to four serotypes. The results imply the need for a policy to promote public hygiene and regularly screen individuals in contact with food items for public consumption.
\end{abstract}

Keywords: Ethiopia, Human, Prevalence, Salmonella, Serogroups, Serotypes

\section{Background}

Salmonellosis is one of the major zoonotic diseases all over the world with annual estimates of 22 million cases and 200,000 deaths due to typhoid fever [1] and 93.8 million cases of gastroenteritis and 155000 deaths due to non-typhoidal Salmonellae (NTS) [2]. In resourcepoor settings of Africa, enteric fever is a public health concern [3] with an incidence of 10-100/100,000 cases per year [1]. Of the NTS, S. Typhimurium and S. Enteritidis are common [4,5], and in 2002 each accounted for approximately $25 \%$ of the human isolates [6].

Correspondence: getadesse1@yahoo.com

Department of Biomedical Sciences, College of Veterinary Medicine and Agriculture, Addis Ababa University, P.O. Box 34, Debre Zeit, Ethiopia
Children, the elderly and immunocompromised individuals are the high risk groups and case fatality rates of $38 \%$ in children [7] and $47 \%$ in adults [8] were recorded. Whilst typhoid fever shows little association with immunocompromise, NTS infections in HIV positive adults are associated with severe invasive diseases [9]. Bacteremia and focal infections are more likely to occur in immunocompromised than in immunocompetent children and infectious arteritis is one of the complications in adults [10]. Higher occurrences of bacteremia were associated with Malaria [11] malnutrition [5,12] and recent antimicrobial use [13].

In Ethiopia, several factors including under and malnutrition, HIV-AIDS, the unhygienic living circumstances and the close relations between humans and 
animals may substantially contribute to the occurrence of Salmonellosis. Although surveillance and monitoring systems are not in place and its epidemiology is not described, qualitative and quantitative syntheses of previous studies could shed light on the occurrence of the disease and the major serotypes that frequently cause infections. The objectives of this study were to systematically review and estimate the prevalence of human Salmonellosis in Ethiopia by using meta-analytical methods. The outcomes of interests were the proportions of Salmonella isolated from diarrheal patients, febrile patients, apparently normal subjects and the dominant serogroups and serotypes.

\section{Methods}

The guidelines of the MOOSE group (Meta-analysis of Observational Studies in Epidemiology) [14] and the PRISMA group (Preferred Reporting Items for Systematic Reviews and Meta-Analyses) [15] were followed in the reviewing. The PRISMA check list was used to ensure inclusion of relevant information (see Additional file 1).

\section{Eligibility criteria}

A study was eligible for quantitative syntheses if (i) its objective was not serotype specific; (ii) it was cross sectional; (iii) the samples were taken from patients that sought medical attention for either reasons of gastroenteritis and/or fever in health care settings or from apparently healthy individuals; (iv) it provided the sample size; (v) it described the microbiological methods; (vi) it provided the numbers of isolates and (vii) it was published in English. Other studies with relevant information on serogroups, serotypes typhoidal and NTS isolates were included in the reviewing.

\section{Literature search strategies}

Published studies were searched in Medline. Non-Medline indexed articles were searched in the lists of references of articles and by using Google scholars. Salmonell* and Ethiopia were the main $\mathrm{MeSH}$ terms in electronic searches. Additional searches were done by using the main MeSH terms with Boolean operators and other terms that included prevalence, incidence, antimicrobial resistance, human, animals, foods and Addis Ababa. The search covered articles published up to November 19, 2013.

\section{Selection of studies}

Initially articles with titles and abstracts that were not relevant to the outcomes of interests were excluded. The full texts of all articles screened for eligibility but one were either downloaded or obtained from the corresponding authors (Dr. Byleyegne Molla, Dr. Endrias
Zewdu and Mr. Bayeh Abera) or from the archives of the College of Health Sciences, School of Medicine, Addis Ababa University. Of the screened articles, duplicates and articles that did not meet the eligibility criteria were excluded.

\section{Data extraction}

The first author, year of publication, year of study, location, setting, sample size, age group, types of samples, microbiological methods, numbers of Salmonella positive samples, serogroups and serotypes were extracted from the eligible studies. The proportions of typhoidal and non-typhoidal Salmonellae, serogroups and serotypes were calculated by using the numbers of isolates as denominators. A serotype was considered to be dominant if its occurrence was more than $5 \%$ of the total serotyped isolates.

\section{Data analysis}

The data were stratified on the basis of feel of relative homogeneity [14] as hospital based and non-hospital based. The hospital based data were further grouped by sample type (stool and blood) and age group (adults and children). To produce conservative estimates, a zero reported for the number of Salmonella positive samples was imputed as 0.5 [16]. The study level prevalence estimates (p) and standard errors (se) were calculated by the following formulae: $p=n p / n$ and se. $=\sqrt{ } p(1-p) / n$ : where $\mathrm{np}=$ the number of positive samples and $\mathrm{n}=$ the number of samples.

\section{Investigation of bias}

The qualities of the microbiological methods of the studies were assessed to determine the extent to which bias is introduced and results in inferential error. The risks of bias across studies were assessed by funnel plots [17] and the Duval and Tweedie non-parametric 'trim and fill' linear random model [18]. The funnel plots were used to visually examine outliers and the tendencies of studies with small sample sizes to show larger prevalence estimates. The Duval and Tweedie method was used to calculate the unbiased estimate.

\section{Heterogeneity analyses}

The variations between studies were assessed by the Galbraith plot [19], the Cochran's Q test and the Inverse variance index $\left(\mathrm{I}^{2}\right)[20]$. The Galbraith plot was used to graphically display the ratio of the prevalence estimates and the standard errors ( $\mathrm{p} / \mathrm{se}$ ) against the reciprocals of the standard errors $(1 / \mathrm{se})$. Because of the reduced power of the Cochran's $Q$ test to test the between-study variation in small number of studies, the significance of the heterogeneities was tested at a 10\% significance level [21]. The percentage of the variation attributable to 
heterogeneity was quantified by the Inverse variance index and values of $25 \%, 50 \%$ and $75 \%$ were considered as low, moderate and high heterogeneity respectively.

\section{Sensitivity tests}

A sensitivity test was done to assess the effects of outliers [22]. The Duval and Tweedie non-parametric linear random effects model [18] and single study omitted influence analyses were done to assess the sensitivities of the pooled prevalence estimates of Salmonella in diarrheal patients and apparently healthy subjects. A study was considered to be influential if the pooled estimate without it was not within the $95 \%$ confidence interval of the overall pooled estimate.

\section{Quantitative data syntheses}

To normalize the distribution of the data and incorporate the influence of sample size on the outcomes, the study level estimates were transformed to logit event estimates $[23,24]$. The logit event estimates and the variances were calculated by the following formulae: $\operatorname{Lp}=\operatorname{Ln}[\mathrm{p} /(1-\mathrm{p})]$ and $V(L p)=1 /(n p)+1 /[n(1-p)]$ where $L p=$ the logit event estimate; $L n=$ the natural logarithm; $p=$ study level prevalence estimate; $\mathrm{V}=$ variance and $\mathrm{n}=$ sample size. The pooled logit event estimates were calculated by the DerSimonian and Laird random effects model [25] and back-transformed to prevalence estimates by the following formula: $\mathrm{p}=\mathrm{e}^{\mathrm{LP}} /\left(\mathrm{e}^{\mathrm{Lp}}+1\right)$ : where $\mathrm{e}=$ the base of the natural logarithm. The $\mathrm{Z}$ test was used to test the significance of the prevalence estimates. The statistical significances of the differences in prevalence estimates between sub-groups were assessed by the Yates corrected Chi Square test [26,27] and the strengths of associations were measured by Odds Ratios (OR). Alpha was set at 0.05 .

Microsoft Office Excel 2007 was used to calculate the study level prevalence estimates and standard errors, the logit event estimates and standard errors and to transform the pooled logit estimates to prevalence estimates. The StatCalc epidemiologic calculator of Epi info ${ }^{\text {mit }}$ (Version 3.5.1, Center for Disease Control, CDC, USA) was used to compare groups. All other analyses were done by using Stata (Version 11.1, Stata Corp, College Station, Texas).

\section{Results}

\section{Eligible and excluded studies}

Figure 1 shows the literature search results and the processes in the selection of eligible studies. A total of 138 studies were found of which 115 were excluded based on the titles and abstracts and one was excluded due to duplication. Of the 22 articles screened for eligibility, one study was excluded for it neither provided the number of samples nor separately presented the serogroups

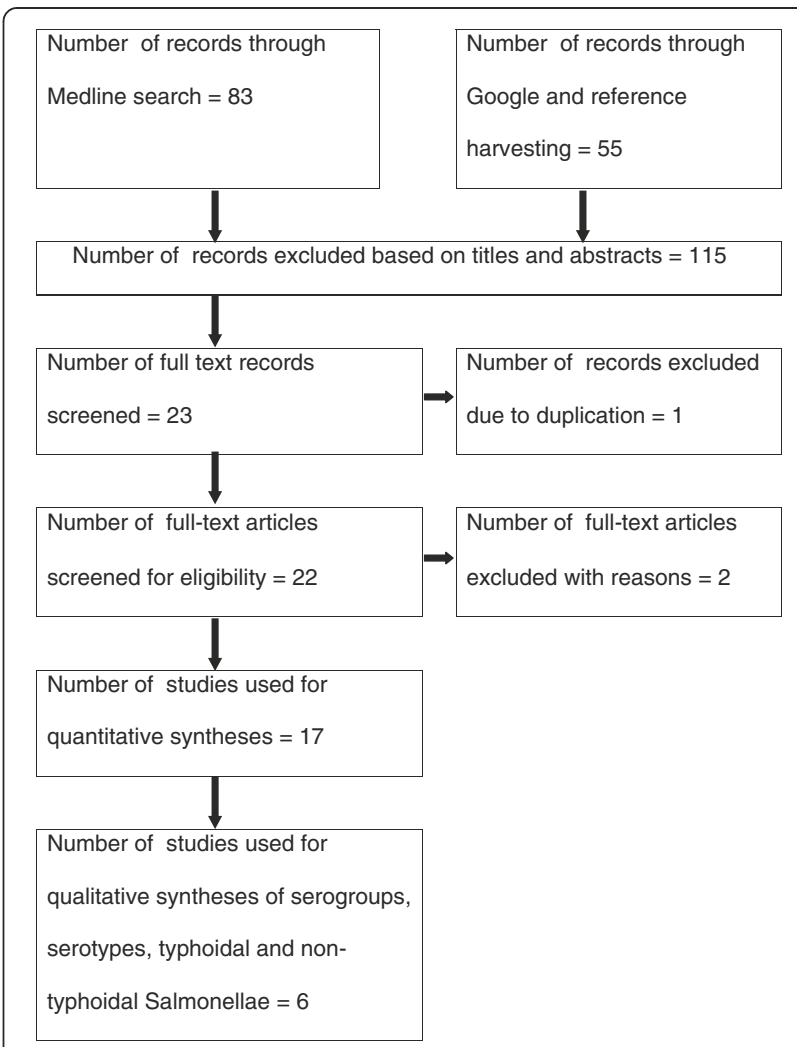

Figure $1 \mathrm{~A}$ flow diagram of the selection of eligible studies.

isolated from patients and controls [28]. Another study was excluded because it was conducted in a rehabilitation camp [29]. A total of twenty studies were considered eligible for qualitative and quantitative syntheses [30-49]. Seven studies [30,32,35-37,41,46] were used to estimate the prevalence of Salmonella in diarrheal patients. Four studies $[31,33,42,46]$ were used to estimate the prevalence of Salmonella in febrile patients. Eight studies [34,37-40,43-45] were used to estimate the prevalence of Salmonella in apparently healthy subjects. Of the hospital based studies, five reported serogroups [32,35,46-48]; six reported the proportions of nontyphoidal and typhoidal Salmonella [32,35,46-49] and two reported serotypes [46,47]. Four non-hospital based studies reported serotypes $[34,40,44,45]$.

\section{Characteristics of the eligible studies}

Table 1 presents the characteristics of the eligible studies. The studies were conducted between 1974 and 2012 in Central, Eastern, Western, Southern and Northern Ethiopia. Except in three studies [47-49], the samples were either stool or blood or both.

Data from 5898 patients and 1528 apparently healthy subjects were considered for quantitative syntheses. The prevalence of Salmonella in stool samples of patients and apparently healthy subjects ranged from $4.5 \%$ to 
Table 1 Characteristics of the eligible studies

\begin{tabular}{|c|c|c|c|c|c|c|c|c|}
\hline First authors & Location & Year of study & Setting & Age group & Sample source & Sample number & Positive & $(\%)$ \\
\hline Ashenafi [30] & Addis Ababa & 1982-1983 & Hospital & Adults & s & 1000 & 45 & 4.5 \\
\hline Ghiorgis [31] & Addis Ababa & na & Hospital & Children & $b$ & 634 & 28 & 4.4 \\
\hline Mache [32] & Addis Ababa & 1995 & Hospital & Adults & s & 700 & 45 & 6.4 \\
\hline Asrat [33] & Addis Ababa & 1996-1998 & Hospital & Adults & $b$ & 1110 & 9 & 0.8 \\
\hline Nyeleti [34] & Addis Ababa & 1999 & ap & Adults & s & 300 & 18 & 6 \\
\hline Mache [35] & Jimma & 2000 & Hospital & Children & s & 384 & 59 & 15.4 \\
\hline Andualem [36] & Addis Ababa & $2000-2001$ & Hospital & All & s & 205 & 22 & 10.7 \\
\hline Awole [37] & Jimma & 2001 & Hospital & Adults & s & 152 & 11 & 7.2 \\
\hline Awole [37] & Jimma & 2001 & ho & Adults & s & 220 & 0 & 0 \\
\hline Birhaneselassie[38] & Dilla & 2002 & fh & Adults & s & 107 & 1 & 0.9 \\
\hline Andargie [39] & Gondar & 2003 & fh & Adults & s & 127 & 0 & 0 \\
\hline Zewdu [40] & Addis Ababa & 2004 & sm & Adults & s & 68 & 5 & 7.4 \\
\hline Reda [41] & Harar & 2007 & Hospital & Adults & s & 244 & 28 & 11.5 \\
\hline Abera [42] & Bahir Dar & 2009 & fh & Adults & s & 384 & 6 & 1.6 \\
\hline Zenebe [43] & Jimma & $2009-2010$ & Hospital & Adults & $b$ & 260 & 1 & 0.4 \\
\hline Addis [44] & Addis Ababa & 2010 & $d f$ & Adults & s & 22 & 3 & 13.6 \\
\hline Dagnew [45] & Gondar & 2012 & fh & Adults & s & 300 & 4 & 1.3 \\
\hline Beyene $[46]^{a}$ & Addis-Jimma & 2006 & Hospital & Children & $s / r$ & 1003 & 48 & 4.8 \\
\hline Beyene $[46]^{a}$ & Addis-Jimma & 2006 & Hospital & Children & $\mathrm{b}$ & 222 & 17 & 7.7 \\
\hline Beyene $[46]^{a}$ & Addis Ababa & 2004-2005 & Hospital & Children & na & na & 48 & na \\
\hline Gebre-yohannes [47] & Addis Ababa & 1974-1981 & Hospital & All & $\mathrm{m}$ & na & 216 & na \\
\hline Gedebou [48] & Addis Ababa & 1975-1980 & Hospital & All & $\mathrm{m}$ & na & 165 & na \\
\hline Wolday [49] & Addis Ababa & 1993-1996 & Hospital & na & $\mathrm{m}$ & na & 110 & na \\
\hline
\end{tabular}

Addis-Jimma = Addis Ababa and Jimma, ap = abattoir personnel, $b=$ blood, $d f=$ dairy farm attendants, fh = food handlers, ho = samples taken in a hospital from patients with complaints other than gastro-enteritis and fever, $\mathrm{m}=$ mixed samples, $\mathrm{na}=$ not available, $\mathrm{s}=\mathrm{stool}, \mathrm{sm}=\mathrm{supermarket}$ personnel, $\mathrm{s} / \mathrm{r}=\mathrm{stool}$ or rectal swabs.

${ }^{a}$ The number of stool and blood samples and Salmonella positive samples were extracted from the Thesis but other data were extracted from the article.

$15.4 \%$ and from $0 \%$ to $13.6 \%$ respectively. Of the 707 Salmonellae isolated from specimens taken from patients, 597 isolates were serogrouped and 329 were serotyped. Of the 37 Salmonellae isolated from apparently healthy subjects, 33 isolates were serotyped.

\section{Risks of bias}

Table 2 presents the microbiological methods employed in the isolation and identification of Salmonella. Pre enrichment was reported in four studies. Two studies reported two selective enrichment media, and six studies reported two plating media. Enrichment with Selenite containing media, plating with Salmonella Shigella agar and Desoxycholate Citrate agar were reported in 12, 7 and 5 of the studies respectively. Only one study reported pre enrichment broth, two selective enrichment and three plating media. Biochemical tests were reported in all studies but one and slide agglutination tests were reported in 10 studies.

Outliers were detected in the funnel plots of the prevalence estimates of Salmonellae isolated from stool samples of diarrheal patients and apparently normal individuals (plots not shown). The pooled prevalence of Salmonella in diarrheal patients was not changed by the Duval and Tweedie method and the lowest and highest single study omitted estimates were $6.75 \%$ and $9.07 \%$ respectively. The pooled prevalence of Salmonella in apparently healthy individuals was slightly higher than the estimate calculated by the Duval and Tweedie method and the lowest and highest single study omitted estimates were $0.58 \%$ and $1.27 \%$ respectively. All single study omitted pooled estimates were within the $95 \%$ confidence intervals of the respective overall pooled estimates in diarrheal patients and apparently normal individuals.

\section{Forest plots}

Figure 2 presents forest plots of the untransformed prevalence estimates of Salmonella isolated from stool samples of diarrheal patients and apparently healthy subjects. The percentage of the variations in prevalence estimates attributable to heterogeneity $\left(\mathrm{I}^{2}\right)$ were $87.3 \%$ in 
Table 2 Microbiological methods used to isolate and identify Salmonella

\begin{tabular}{|c|c|c|c|c|}
\hline First author & Pre-enrichment & Selective and differential media & BT & SAT \\
\hline Ashenafi [30] & $\mathrm{nr}$ & $\mathrm{SB}, \mathrm{MA}, \mathrm{BGA}$ & yes & Yes \\
\hline Mache [32] & $\mathrm{nr}$ & $\mathrm{SF}, \mathrm{MA}, \mathrm{BGA}, \mathrm{SSA}$ & yes & Yes \\
\hline Mache [35] & $\mathrm{nr}$ & SB, MA, SSA & yes & Yes \\
\hline Andualem [36] & $\mathrm{nr}$ & SF, MA, SSA & yes & $\mathrm{nr}$ \\
\hline Awole [37] & $\mathrm{nr}$ & MA, DCA, SSA & Yes & $\mathrm{nr}$ \\
\hline Beyene [46] & $\mathrm{nr}$ & SF, DCA, XLD & yes & Yes \\
\hline Reda [41] & $\mathrm{nr}$ & SF, DCA, XLD & yes & $\mathrm{nr}$ \\
\hline Asrat [33] & $\mathrm{nr}$ & $\mathrm{SB}, \mathrm{MA}, \mathrm{BGA}$ & yes & Yes \\
\hline Zenebe [43] & $\mathrm{BHI}$ & $\mathrm{BA}, \mathrm{MA}$ & yes & Yes \\
\hline Beyene [46] & $\mathrm{BHI}$ & DCA, XLD & yes & Yes \\
\hline Nyeleti [34]. & $\mathrm{nr}$ & $R V, M A, B P L S$ & yes & Yes \\
\hline Awole [37] & $\mathrm{nr}$ & MA, DCA, SSA & Yes & $\mathrm{nr}$ \\
\hline Berhane selassie [38] & $\mathrm{nr}$ & SB, DCA & yes & Yes \\
\hline Andargie [39] & $\mathrm{nr}$ & $M A, B A, S S A$ & $\mathrm{nr}$ & $\mathrm{nr}$ \\
\hline Zewdu [40] & BPW & $\mathrm{SC}, \mathrm{RV}, \mathrm{BPLS}, \mathrm{XLD}, \mathrm{RA}$ & yes & Yes \\
\hline Abera [42] & $\mathrm{nr}$ & SF, SSA & $\mathrm{nr}$ & $\mathrm{nr}$ \\
\hline Addis [44] & BPW & SC, RV, XLD & yes & $\mathrm{nr}$ \\
\hline Dagnew [45] & $\mathrm{nr}$ & SF, SSA & yes & $\mathrm{nr}$ \\
\hline
\end{tabular}

$\mathrm{BA}=$ Blood agar, BHI = Brain Heart infusion agar, BGA = Brilliant Green agar, BPLS = Brilliant Phenol Lactose -Sucrose agar, BPW $=$ Buffered Peptone Water, $\mathrm{BT}=$ Biochemical test, $\mathrm{DCA}=$ Desoxycholate Citrate agar, $\mathrm{MA}=$ MacConkey agar, $\mathrm{nr}=$ not reported, $\mathrm{RA}=$ Rambach agar, $\mathrm{RV}=$ Rappaport Vassilliadis, $\mathrm{SAT}=\mathrm{Slide}$ Agglutination Test; SSA = Salmonella Shigella agar, SB = Selenite broth, SC = Selenite Cystine broth, SF = Selenite-F broth, XLD = Xylose Lysine Desoxycholate agar .

Study ID
Ashenafi [30]
Mache [32]
Mache [35]
Andualem [36]
Awole [37]
Beyene [46]
Reda [41]
Overall $\left(I^{2}=87.3 \%, p=0.000\right)$

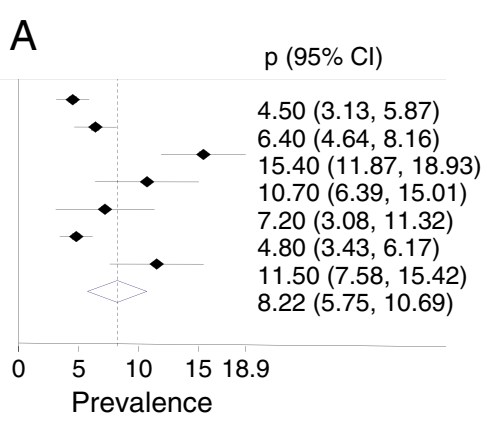

Study ID
Nyeleti [34]
Awole [37]
Birhanesellassie [38]
Andargie [39]
Zewdu [40]
Abera [42]
Addis [44]
Dagnew [45]
Overall $\left(I^{2}=83.7 \%, p=0.000\right)$

B

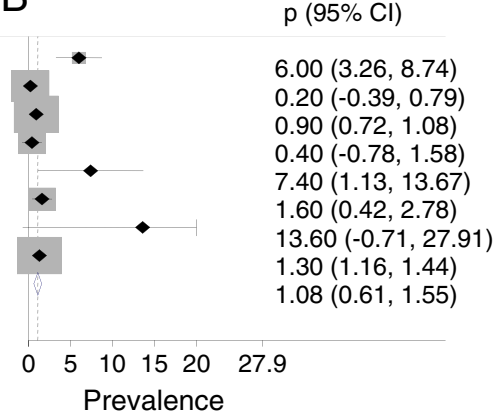

Figure 2 Forest plot of the prevalence of Salmonella isolated from stool samples of patients (A) and apparently healthy subjects (B). 'The upper confidence limit of Addis [44] is off the scale and truncated. 
diarrheal patients and $83.7 \%$ in apparently normal subjects. All study level prevalence estimates of Salmonella in diarrheal patients were significantly different from zero $(\mathrm{p}<0.05)$. Three study level prevalence estimates of Salmonella in apparently healthy subjects were not significantly different from zero $(\mathrm{p}>0.05)$.

\section{Pooled prevalence estimates}

The pooled estimates calculated based on the untransformed and logit transformed estimates are presented in Table 3. The differences in the pooled estimates of the untransformed and transformed data were negligible. The prevalence of Salmonella was higher in diarrheal children than in diarrheal adults $\left(X^{2}=10.93 ; \mathrm{p}=0.000\right.$; $\mathrm{OR}=1.59$ (95\% $\mathrm{CI}=1.20,2.10)$, in febrile children than in febrile adults $\left(\mathrm{X}^{2}=48.27 ; \mathrm{p}=0.000 ; \mathrm{OR}=8.16(95 \%\right.$ $\mathrm{CI}=3.97,17.25)$ and in individuals exposed to animal products or animals (super market personnel, dairy farm attendants and abattoir personnel) than in food handlers $\left(\mathrm{X}^{2}=27.93 ; \mathrm{p}=0.000 ; \mathrm{OR}=5.62(95 \% \mathrm{CI}=2.70,11.88)\right.$.

\section{Serogroups and serotypes}

Typhoidal Salmonella (S. Typhi) accounted for $42.1 \%$ of the total isolates (Table 4) and for $8.7 \%$ of the isolates of children origin. Six serogroups were identified from patients (Table 5). Serogroup D occurred more frequently than serogroups $C$ and $B$. In children, serogroup $C$ ranked first followed by serogroup D. Thirty serovars were identified from specimens taken from patients of which S. Concord, S. Typhi, S. Typhimurium and S. Paratyphi were the first four dominant serotypes that accounted for $82.1 \%$ of the serotyped isolates (Table 6). In non hospital based studies, six serovars were identified: S. Anatum (7/33), S. Dublin (4/33), S. Meleagridis (5/33), S. Newport (5/33), S. Rough form (2/33) and $S$. Typhi (10/33).

\section{Discussion}

Studies on human Salmonellosis in Ethiopia began in the 1970s. However, the number of studies so far carried out is small and do not include all segments of the population and geographic regions of the country. Most studies were carried out in Addis Ababa and risk factors that potentially influence the occurrence of the disease including the diversity of serovars were not sufficiently addressed to provide a comprehensive picture of the epidemiology of the disease. In addition to the small number of studies, the aggregate reporting and lack of distinct data by sample type and age group were constraints in estimating the prevalence of serogroups and serotypes.

The microbiological methods employed in the studies might have underestimated the numbers of Salmonella positive samples. The use of pre enrichment broth increases culture sensitivity and the numbers of isolates could differ by types of media [50]. Salmonella strains have different characteristics in enrichment media and there could be a differential recovery of one strain over another [51]. As the rates of isolation of strains differ in different media versions, multiple enrichment protocols were suggested to ensure the isolation of different strains [52]. The recovery rate of Salmonella, the sensitivities and positive predictive values of plating media were also reported to be higher after enrichment than direct culture [53].

The substantial variations in prevalence estimates attributable to heterogeneity could be due to differences in the study populations and the microbiological methods used to detect Salmonella. However, the pooled estimates were not sensitive to the effects of outliers and depict the importance of the disease as the random effects model considers the studies as samples of all potential studies.

The pooled prevalence of Salmonella in diarrheal patients is comparable with the estimate for SSA (8.36\%)

Table 3 Pooled prevalence estimates of Salmonella in patients that sought medical attention and in carriers

\begin{tabular}{|c|c|c|c|c|}
\hline \multirow[t]{2}{*}{ Group } & \multicolumn{2}{|c|}{ Untransformed data } & \multicolumn{2}{|c|}{ Logit transformed data ${ }^{c}$} \\
\hline & Prevalence $(95 \% \mathrm{CI})$ & $I^{2}, p$ value ${ }^{d}$ & Prevalence $(95 \% \mathrm{Cl})$ & $I^{2}, p$ value $^{d}$ \\
\hline Diarrheal patients ${ }^{a}$ & $8.22(5.75,10.69)$ & $87.3,0.000$ & $7.93(5.30,11.70)$ & $90.8,0.000$ \\
\hline Diarrheal adults & $5.58(3.99,7.17)$ & $44.6,0.164$ & $5.68(4.26,7.53)$ & $49.3,0.139$ \\
\hline Diarrheal children & $9.97(-0.41,20.36)$ & $96.7,0.000$ & $8.72(2.64,25.18)$ & $97.5,0.000$ \\
\hline Febrile adults & $0.66(0.19,1.13)$ & $0.0,0.424$ & $0.76(0.41,1.40)$ & $0.0,0.516$ \\
\hline Febrile children & $5.66(2.52,8.80)$ & $64.4,0.094$ & $5.71(3.31,9.68)$ & $70.5,0.066$ \\
\hline Over all carriers & $1.08(0.61,1.55)$ & $83.7,0.000$ & $2.75(1.23,6.17)$ & $76.1,0.000$ \\
\hline Food handlers & $1.09(0.73,1.44)$ & $79.2,0.002$ & $1.33(0.75,2.36)$ & $0.0,0.793$ \\
\hline Others $^{b}$ & $6.45(3.97,8.92)$ & $0.0,0.562$ & $6.83(4.69,9.85)$ & $0.0,0.391$ \\
\hline
\end{tabular}

${ }^{\mathrm{a}}$ Diarrheal adults and children.

b Individuals in contact with animal products or animals.

${ }^{\mathrm{c}}$ The pooled prevalence estimates of the logit transformed data were the summary measures.

${ }^{d}$ The $p$ values are estimated by the Cochran's $Q$ test. 
Table 4 Frequencies and percentages of $S$. Typhi isolated from samples taken from patients

\begin{tabular}{lcccc}
\hline $\begin{array}{l}\text { Study } \\
\text { year }\end{array}$ & $\begin{array}{c}\text { Number of } \\
\text { isolates }\end{array}$ & $\begin{array}{c}\text { Number of } \text { S. } \\
\text { Typhi }\end{array}$ & $\%$ & Authors \\
\hline $1975-1980$ & 164 & 123 & 75 & 48 \\
$1974-1981$ & 216 & 105 & 48.6 & 47 \\
$1993-1996$ & 110 & 48 & 43.6 & 49 \\
1995 & 45 & 7 & 15.6 & 32 \\
2000 & 59 & 13 & 22 & 35 \\
$2004-2006$ & 113 & 2 & 1.8 & 46 \\
$1974-2006$ & 707 & 298 & 42.1 & \\
\hline
\end{tabular}

[54]. The present estimate appears to be lower than its actual occurrence due to the apparently lower sensitivities of the microbiological methods used in most of the studies. In addition, several patients do not seek medical attention for less severe gastroenteritis and are unable to cover medical costs for even severe cases. However, the widespread occurrences of several factors including malnutrition and under nutrition, HIV-AIDS, the close relationship between man and animals, the widespread backyard slaughtering practices, the raw meat consumption habits, the unhygienic food handling practices and the water sources of the larger segment of the population are suggestive evidences of its higher occurrence than is estimated in this study.

The higher occurrence of Salmonellosis in children compared to adults suggests a higher vulnerability of children to Salmonella infections. Disseminated diseases were reported in children with severe protein-energy malnutrition [55]. The bacterium was isolated from stool samples of pediatric patients [56] and demonstrated in malarial blood smears of febrile children [57]. Regardless of the small number of studies considered in this study, the pooled estimates show the importance of the disease in Ethiopian children as is the case in other countries in SSA [58].

Salmonellae were isolated from individuals working in food catering establishments, super market workers, dairy farm attendants and abattoir personnel. Although these individuals could either be asymptomatic or precocious or acute or convalescent or chronic carriers, all are potential sources of outbreaks. In the USA, a few food service employees were implicated for an outbreak that caused 617 (6.3\%) illnesses [59].

The proportion of $S$. Typhi isolates tends to decline as of the 1970s while NTS infections show a relative increase. As the data were drawn from urban areas, improvements in hygienic and sanitary measures practiced in the years after the 1970s might have reduced the occurrence of typhoidal infections in urban areas. However, the proportional decreases in typhoidal infections do not reflect the substantial improvements in the hygienic and sanitary practices of the general population.

Serogroups D, C and B were the major serogroups and their occurrences differ by age group. Whilst serogroup $\mathrm{C}$ ranked first in children $[35,46]$, serogroup D was dominant in samples predominantly taken from adults [47]. Higher indexes of invasion were also recorded for serogroup D [48] and serogroup C [46]. In addition to the differences by age group, the proportions of serogroups may differ by sample type and study years.

$S$. Concord and $S$. Typhimurium were the first and third ranking NTS isolated from patients. In a global analysis of reports from 26 countries, $S$. Enteritidis (65\%) and $S$. Typhimurium (12\%) were the dominant serotypes isolated from 2000 to 2002 [6]. In Ethiopia, S. Enteritidis accounted for $1.8 \%$ of the isolates $[46,47]$ and less than five isolates were isolated from samples of cattle [60], sheep [61], pigs [62,63] and chicken [64]. The differences in the preponderance of serovars across countries could be due to the variations in the epidemiology of the serotypes that may involve animal as well as environmental factors.

$S$. Concord was the first ranking serovar isolated from patients. Its occurrence was higher in samples taken from children [46] than in samples predominantly from adults [47]. The bacterium was isolated from Ethiopian children adopted in several European countries and the

Table 5 Frequencies (\%) of serogroups identified from samples taken from patients

\begin{tabular}{|c|c|c|c|c|c|c|}
\hline \multirow[t]{3}{*}{ Serogroup } & \multicolumn{6}{|c|}{ Number and percentage of serogroups } \\
\hline & [48] & [47] & [32] & [35] & {$[46]$} & Total (\%) \\
\hline & No. (\%) & No. (\%) & No. (\%) & No. (\%) & No. (\%) & No. (\%) \\
\hline $\bar{A}$ & $7(4.3)$ & $4(1.9)$ & $4(8.9)$ & $5(8.5)$ & 0 & $20(3.4)$ \\
\hline B & $16(9.8)$ & $44(20.4)$ & $11(24.4)$ & $17(28.8)$ & $13(11.5)$ & 101(16.9) \\
\hline C & $17(10.4)$ & $42(19.4)$ & $14(31.1)$ & $13(22)$ & $86(76.1)$ & $171(28.6)$ \\
\hline $\mathrm{D}$ & $123(75)$ & $120(55.6)$ & $13(28.9)$ & 21(35.6) & $9(8)$ & $286(47.9)$ \\
\hline E & $1(0.6)$ & $6(2.8)$ & $3(6.7)$ & $3(5.1)$ & $2(1.8)$ & $15(2.5)$ \\
\hline M & 0 & 0 & 0 & 0 & $3(2.7)$ & $3(0.5)$ \\
\hline Total & 164 & 216 & 45 & 59 & 113 & 597 \\
\hline
\end{tabular}


Table 6 Frequencies (\%) of serotypes isolated from samples taken from patients

\begin{tabular}{lccc}
\hline Serotypes & \multicolumn{3}{c}{ Number of isolates } \\
\cline { 2 - 4 } & [47] & {$[46]$} & Total (\%) \\
\hline S. Concord & $27(12.5)$ & $85(75.2)$ & $112(34)$ \\
S. Typhi & $105(48.6)$ & $2(1.8)$ & $107(32.5)$ \\
S. Typhimurium & $24(11.1)$ & $7(6.2)$ & $31(9.4)$ \\
S. Paratyphi & $18(8.3)$ & $2(1.8)$ & $20(6.1)$ \\
Others & $42(19.4)$ & $17(15.0)$ & $59(17.9)$ \\
Total & 216 & 113 & $329(100)$ \\
\hline
\end{tabular}

USA [65-69] but not demonstrated in samples taken from domestic food animals and food items of animal origin. As $S$. Concord was reported to be highly invasive [46] and multi drug resistant [46,47,65-69], it could be a serious cause of morbidity and mortality in children.

$S$. Typhi and $S$. Paratyphi are causes of enteric fever with similar disease patterns [69]. In the 1980s, typhoid fever was diagnosed in $1.1 \%$ of the Ethiopian immigrants in Israel [70] and a case fatality rate of $15.7 \%$ was reported in hospital admitted Ethiopian children [71]. In a recent study on patients with febrile illnesses, typhoid fever was recorded in $5.85 \%$ of the patients with a higher occurrence in children aged three to 14 years (6.6\%) compared to children aged 15 to 17 years (1.1\%) [72]. Although a systematic epidemiological study is not available, the lower living standard of the general population is a suggestive evidence that enteric fever is a threat in present day Ethiopia.

$S$. Typhimurium was the third ranking serovar that accounted for $15.3 \%$ of the NTS isolates $[46,47]$ and its occurrence is within the range of its global preponderance (10-30\%) [73].This serotype was isolated from slaughtered cattle, sheep and camels [56-58,74-76], minced beef $[38,64]$ and chicken samples $[40,77,78]$ in Ethiopia and reported to be a common cause of invasive disease $[4,12]$ with a higher mortality rate in AIDS patients [79].

Of the isolates recovered from stool samples of carriers, $S$. Dublin and $S$. Newport could be of significant public health concerns. $S$. Newport was a cause of an outbreak in Gondar College of Health Sciences, Ethiopia where 79 (23\%) students had manifest disease [80] and it was isolated in meat samples collected from supermarkets [40] and in samples taken from slaughtered animals $[63,74,75]$. S. Dublin was isolated from human clinical samples [47], slaughtered cattle [34,60] and from meats collected from markets [34,40,64]. Significant associations of $S$. Dublin infection with raw milk consumption habits, higher invasion (65\%), hospital admission (78.8\%) and mortality rates (19.5\%) were reported [81].

\section{Limitations and implications of the study}

The patient data were collected from Hospitals that provided services to both urban and rural inhabitants but the origin of the study subjects were not reported. However, it appears that most patients could be from urban areas because of the relatively better accesses to health care settings. Therefore, the pooled estimates are more applicable to patients in urban areas than to patients in rural areas.

The results of this study have several implications in clinical practices, policy issues and intervention measures and in research undertakings. First, as drug sensitivity tests are not routinely carried out in several clinical settings of the country, antimicrobials known to be effective against the dominant serovars could be used as empirical therapeutic agents. Secondly, the considerable occurrences of Salmonella in patients and apparently healthy subjects imply the need for a policy and intervention measures to promote public hygiene and regularly screen individuals that are in contact with food items meant for public consumption. In addition, the limited number of studies and the occurrence of serotypes of significant national and international concerns $[46,62,63,65-68]$, entail the need for a large scale study to describe the epidemiology of the disease at a national level. The pooled estimates are more reliable than the single study estimates and could be used in the design of further studies.

\section{Conclusion}

The prevalence of Salmonellosis is considerable and a few serotypes that included $S$. Concord, $S$. Typhi, $S$. Typhimurium, and $S$. Paratyphi are the major causes of infections. There is a need of a policy and intervention measures to promote public hygiene and regularly screen individuals in contact with food items for public consumption. Further studies are required to adequately describe the epidemiology of human Salmonellosis in Ethiopia.

\section{Additional file}

Additional file 1: PRISMA Checklist.

Competing interests

The author declares no competing interests.

Author's contributions

GT conceived the study design, searched the literature, extracted the data, analyzed the data, interpreted the results and drafted the manuscript.

\section{Acknowledgements}

I thank Dr. Byleyegne Molla, Dr. Sefinew Alemu, Dr. Endrias Zewdu and Mr. Bayeh Abera for supplying me with their articles and Dr. Tesfaye Sisay for his help in literature search. 
Received: 4 April 2013 Accepted: 7 February 2014

Published: 19 February 2014

\section{References}

1. Crump JA, Luby SP, Mintz ED: The global burden of typhoid fever. Bull World Health Organ 2004, 82:346-353.

2. Majowicz SE, Musto J, Scallan E, Angulo FJ, Kirk M, O'Brien SJ, Jones TF, Fazil A, Hoekstra RM: The global burden of nontyphoidal Salmonella gastroenteritis. Clin Infect Dis 2010, 50:882-889.

3. Kariuki S: Typhoid fever in sub-Saharan Africa: challenges of diagnosis and management of infections (Review). J Infect Dev Ctries 2008, 2:443-447.

4. Gordon MA, Graham SM, Walsh AL, Wilson L, Phiri A, Molyneux E, Zijlstra EE, Heyderman RS, Hart CA, Molyneux ME: Epidemics of invasive Salmonella enterica serovar Enteritidis and S. enterica serovar Typhimurium infection associated with multidrug resistance among adults and children in Malawi. Clin Infect Dis 2008, 46:963-969.

5. Brent AJ, Oundo JO, Mwangi I, Ochola L, Lowe B, Berkley JA: Salmonella bacteremia in Kenyan children. Pediatr Infect Dis J 2006, 25:230-236.

6. Galanis E, Lo Fo Wong DM, Patrick ME, Binsztein N, Cieslik A, Chalermchikit T, Aidara-Kane A, Ellis A, Angulo FJ, Wegener HC: Web-based surveillance and global Salmonella distribution, 2000-2002. Emerg Infect Dis 2006, 12:381-388.

7. Walsh AL, Phiri AJ, Graham SM, Molyneux EM, Molyneux ME: Bacteremia in febrile Malawian children: clinical and microbiologic features. Pediatr Infect Dis J 2000, 19:312-318.

8. Gordon MA, Banda HT, Gondwe M, Gordon SB, Boeree MJ, Walsh AL, Corkill JE, Hart CA, Gilks CF, Molyneux ME: Non-typhoidal salmonella bacteraemia among HIV-infected Malawian adults: high mortality and frequent recrudescence. AIDS 2002, 16:1633-1641.

9. Gordon MA: Salmonella infections in immunocompromised adults. J Infect 2008, 56:413-422. doi:10.1016/j.jinf.2008.03.012.

10. Hohmann EL: Nontyphoidal Salmonellosis. Clin Infect Dis 2001, 32:263-269.

11. Enwere G, Biney E, Cheung YB, Zaman SM, Okoko B, Oluwalana C, Vaughan A, Greenwood B, Adegbola R, Cutts FT: Epidemiologic and clinical characteristics of community acquired invasive bacterial infections in children aged 2-29 months in the Gambia. Pediatr Infect Dis J 2006, 25:700-705.

12. Berkley JA, Lowe BS, Mwangi I, Williams T, Bauni E, Mwarumba S, Ngetsa C, Slack MP, Njenga S, Hart CA: Bacteremia among children admitted to a rural hospital in Kenya. N Engl J Med 2005, 352:39-47.

13. Pavia AT, Shipman LD, Wells JG, Puhr ND, Smith JD, McKinley TW, Tauxe RV: Epidemiologic evidence that prior antimicrobial exposure decreases resistance to infection by antimicrobial-sensitive Salmonella. J Infect Dis 1990, 161:255-260.

14. Stroup DF, Berlin JA, Morton SC, Olkin I, Williamson GD, Rennie D, Moher D, Becker BJ, Sipe TA, Thacker SB: Meta-analysis of observational studies in epidemiology: a proposal for reporting. JAMA 2000, 283:2008-2012.

15. Moher D, Liberati A, Tetzlaff J, Altman DG, The PRISMA Group: Preferred Reporting items for systematic reviews and meta-analyses: the PRISMA statement. PLoS Med 2009, 6:e1000097. doi:10.1371/journal.pmed.1000097.

16. Tricco AC, Ng CH, Gilca V, Anonychuk A, Pham B, Berliner S: Canadian oncogenic human papilloma virus cervical infection prevalence: systematic review and meta-analysis. BMC Infect Dis 2011, 11:235. doi:10.1186/1471-2334-11-235.

17. Sterne JAC, Roger M, Harbord RM: Funnel plots in meta-analysis. Stata J 2004, 4:127-141.

18. Littell JH, Corcoran J, Pillai V: Systematic Reviews and Meta Analyses. New York: Oxford University Press; 2008.

19. Galbraith RF: $A$ note on graphical presentation of estimated odds ratios from several clinical trials. Stat Med 1988, 7:889-894.

20. Higgins JP, Thompson SG: Quantifying heterogeneity in a meta-analysis. Stat Med 2002, 21:1539-1558.

21. Leandro G: Meta-analysis in medical research. The handbook for the understanding and practice of meta-analysis. Massachusetts: Blackwell Publishing Ltd; 2005.

22. Wilson DB: Meta-Analysis. In Handbook of Quantitative Criminology. Edited by Piquero AR, Weisburd D. New York: Springer Science+Business Media; 2010:181-208.

23. Calvo-Muñoz I, Gómez-Conesa A, Sánchez-Meca J: Prevalence of low back pain in children and adolescents: a meta-analysis. BMC Pediatr 2013, 13:14. doi:10.1186/1471-2431-13-14.
24. Hurley JC: Lack of impact of selective digestive decontamination on Pseudomonas aeruginosa ventilator associated pneumonia: benchmarking the evidence base. J Antimicrob Chemother 2011, 66:1365-1373.

25. DerSimonian R, Laird N: Meta-analysis in clinical trials. Control Clin Trials 1986, 7:177-188

26. Yang Y, Li X, Zhou F, Jin Q, Gao L: Prevalence of drug-resistant tuberculosis in mainland China: systematic review and meta-analysis. PLOS ONE 2011, 6:e20343. doi:10.1371/journal.pone.0020343.

27. Gao L, Zhang L, Jin Q: Meta-analysis: prevalence of HIV infection and syphilis among MSM in China. Sex Transm Infect 2009, 85:354-358. doi:10.1136/sti.2008.034702

28. Asrat D: Shigella and Salmonella serogroups and their antibiotic susceptibility patterns in Ethiopia. East Mediterr Health J 2008, 14:760-767.

29. Desenclos JC, Zergabachew A, Desmoulins B, Chouteau L, Desve G, Admassu M: Clinical, microbiological and antibiotic susceptibility patterns of diarrhoea in Korem, Ethiopia. J Trop Med Hyg 1988, 91:296-301.

30. Ashenafi M, Gedebou M: Salmonella and Shigella in adult diarrhoea in Addis Ababa- prevalence and antibiograms. Trans R Soc Trop Med Hyg 1985, 79:719-721.

31. Ghiorghis B, Geyid A, Haile M: Bacteraemia in febrile out-patient children. East Afr Med J 1992, 69:74-77.

32. Mache A, Mengistu Y, Cowley C: Salmonella serogroups identified from adult diarrhoeal out-patients in Addis Ababa, Ethiopia: antibiotic resistance and plasmid profile analysis. East Afr Med J 1997, 74:183-186.

33. Asrat $D$, Amanuel $Y W$ : Prevalence and antibiotic susceptibility pattern of bacterial isolates from blood culture in Tikur Anbassa Hospital, Addis Ababa, Ethiopia. Ethiop Med J 2001, 39:97-104.

34. Nyeleti C, Molla B, Hildebrandt G, Kleer J: The prevalence and distribution of Salmonellae in slaughtered cattle, slaughterhouse personnel and minced beef in Addis Ababa (Ethiopia). Bull Anim Health Prod Afr 2000, 48:19-24.

35. Mache A: Salmonella serogroup and their antibiotic resistance patterns isolated from diarrhoeal stools of pediatric out patients in Jimma Hospital and Jimma Health Center, South West Ethiopia. Ethiop J Health Sci 2002, 37:37-45.

36. Andualem B, Geyid A: Antimicrobial responses of Yersinia enterocolitica isolates in comparison to other commonly encountered bacteria that causes diarrhoea. East Afr Med J 2005, 82:241-246.

37. Awole M, Gebre-Selassie S, Kassa T, Kibru G: Isolation of potential bacterial pathogens from the stool of HIV-infected and HIV-non-infected patients and their antimicrobial susceptibility patterns in Jimma Hospital, Southwest Ethiopia. Ethiop Med J 2002, 40:353-364.

38. Birhaneselassie M, Williams B: A study of Salmonella carriage among asymptomatic food-handlers in Southern Ethiopia. IJNFS 2013, 2:243-245. doi:10.11648/j.jinfs.20130205.15.

39. Andargie G, Kassu A, Moges F, Tiruneh M, Huruy K: Prevalence of bacteria and intestinal parasites among food-handlers in Gondar town, Northwest Ethiopia. J Health Popul Nutr 2008, 26:451-455.

40. Zewdu E, Cornelius P: Antimicrobial resistance pattern of Salmonella serotypes isolated from food items and personnel in Addis Ababa, Ethiopia. Trop Anim Health Prod 2009, 41:241-249.

41. Reda AA, Seyoum B, Jemal Yimam J, Andualem G, Fiseha S, Jean-Michel Vandeweerd JM: Antibiotic susceptibility patterns of Salmonella and Shigella isolates in Harar, Eastern Ethiopia. J Infect Dis Immun 2011, 3:134-139.

42. Abera B, Biadegelgen F, Bezabih B: Prevalence of Salmonella typhi and intestinal parasites among food handlers in Bahir Dar Town, Northwest Ethiopia. Ethiop J Health Dev 2010, 24:46-50.

43. Zenebe T, Kannan S, Yilma D, Beyene G: Invasive bacterial pathogens and their antibiotic susceptibility patterns in Jimma University specialized hospital, Jimma, Southwest Ethiopia. Ethiop J Health Sci 2011, 21:2-8.

44. Addis Z, Kebede N, Worku Z, Gezahegn H, Yirsaw A, Kassa T: Prevalence and antimicrobial resistance of Salmonella isolated from lactating cows and in contact humans in dairy farms of Addis Ababa: a cross sectional study. BMC Infect Dis 2011, 11:222. doi:10.1186/1471-2334-11-222.

45. Dagnew M, Tiruneh M, Moges F, Gizachew M: Bacterial profile and antimicrobial susceptibility pattern among food handlers at Gondar University Cafeteria, Northwest Ethiopia. J Infect Dis Ther 2013, 1:105. doi:10.4172/jidt.1000105. 
46. Beyene G, Nair S, Asrat D, Mengistu Y, Engers H, Wain J: Multidrug resistant Salmonella Concord is a major cause of salmonellosis in children in Ethiopia. J Infect Dev Ctries 2011, 5:23-33.

47. Gebre-Yohannes A: Salmonella from Ethiopia: prevalent species and their susceptibility to drugs. Ethiop Med J 1985, 23:97-102.

48. Gedebou M, Tassew A: Antimicrobial resistance and $R$ factor of Salmonella isolates from Addis Ababa. Ethiop Med J 1981, 19:77-85.

49. Wolday D: Increase in the incidence of multidrug-resistant salmonellae in Ethiopia. J Antimicrob Chemother 1998, 41:421-423.

50. Hoorfar D, Baggesen DL: Importance of pre-enrichment media for isolation of Salmonella spp. from swine and poultry. FEMS Microbiol Lett 1988, 169:125-130

51. Singer RS, Mayer AE, Hanson TE, Isaacson RE: Do microbial interactions and cultivation media decrease the accuracy of Salmonella surveillance systems and outbreak investigations? J Food Prot 2009, 72:707-713.

52. Gorski L: Selective enrichment media bias the types of Salmonella enterica strains isolated from mixed strain cultures and complex enrichment broths. PLoS One 2012, 7:e34722. doi:10.1371/journal. pone.0034722

53. Ruiz J, Núnñez M, Díaz J, Lorente I, Pérez J, Gómez J: Comparison of Five Plating Media for Isolation of Salmonella Species from Human Stools. J Clin Microbiol 1996, 34:686-688.

54. Fletcher S, Stark D, Ellis J: Prevalence of gastrointestinal pathogens in Sub-Saharan Africa: systematic review and meta-analysis. J Public Health Africa 2011, 2. doi:10.4081/jphia.2011.e30.

55. Shimeles D, Lulseged S: Clinical profile and pattern of infection in Ethiopian children with severe protein-energy malnutrition. East Afr Med J 1994, 71:264-267.

56. Shimelis D, Tadesse $Y$ : Clinical profile of acute renal failure in children admitted to the department of pediatrics, Tikur Anbessa Hospital. Ethiop Med J 2004, 42:17-22.

57. Aarsland SJ, Castellanos-Gonzalez A, Lockamy KP, Mulu-Droppers R, Mulu M, White AC, Cabada MM: Treatable bacterial infections are under recognized causes of fever in Ethiopian children. Am J Trop Med Hyg 2012, 87:128-133.

58. Morpeth SC, Ramadhani HO, Crump JA: Invasive non-Typhi Salmonella disease in Africa. Clin Infect Dis 2009, 49:606-611.

59. Beatty ME, Shevick G, Shupe-Ricksecker K, Bannister E, Tulu A, Lancaster K, Alexander N, Zellner DE, Lyszkowicz E, Braden CR: Large Salmonella Enteritidis outbreak with prolonged transmission attributed to an infected food handler, Texas, 2002. Epidemiol Infect 2009, 137:417-427.

60. Alemayehu D, Molla B, Muckle A: Prevalence and antimicrobial resistance pattern of Salmonella isolates from apparently healthy slaughtered cattle in Ethiopia. Trop Anim Health Prod 2003, 35:309-319.

61. Molla W, Molla B, Alemayehu D, Muckle A, Cole L, Wilkie E: Occurrence and antimicrobial resistance of Salmonella serovars in apparently healthy slaughtered sheep and goats of central Ethiopia. Trop Anim Health Prod 2006, 38:455-462.

62. Aragaw K, Molla B, Muckle A, Cole L, Wilkie E, Poppe C, Kleer J, Hildebrandt $\mathrm{G}$ : The characterization of Salmonella serovars isolated from apparently healthy slaughtered pigs at Addis Ababa abattoir, Ethiopia. Prev Vet Med 2007, 82:252-261.

63. Molla B, Berhanu A, Muckle A, Cole L, Wilkie E, Kleer J, Hildebrandt G: Multidrug resistance and distribution of Salmonella serovars in slaughtered pigs. J Vet Med B Infect Dis Vet Public Health 2006, 53:28-33.

64. Molla B, Kleer J, Sinell H: Occurrence, distribution and level of Salmonella in selected food items in Addis Ababa (Ethiopia). Fleischwirtsch Int 1999, 4:37-39.

65. Fabre L, Delauné A, Espié E, Nygard K, Pardos M, Polomack L, Guesnier F, Galimand M, Lassen J, Weill FX: Chromosomal integration of the extended-spectrum beta-lactamase gene blaCTX-M-15 in Salmonella enterica serotype Concord isolates from internationally adopted children. Antimicrob Agents Chemother 2009, 53:1808-1816.

66. Hendriksen RS, Mikoleit M, Kornschober C, Rickert RL, Duyne SV, Kjelsø C, Hasman H, Cormican M, Mevius D, Threlfall J, Angulo FJ, Aarestrup FM: Emergence of multidrug-resistant Salmonella Concord infections in Europe and the United States in children adopted from Ethiopia, 2003-2007. Pediatr Infect Dis J 2009, 28:814-818.

67. Hendriksen RS, Kjelsø C, Torpdahl M, Ethelberg S, Mølbak K, Aarestrup FM: Upsurge of infections caused by Salmonella Concord among Ethiopian adoptees in Denmark. Euro Surveill 2010, 15:19587.
68. Vanhoof R, Gillis P, Stévart O, Boland C, Vandenberg O, Fux F, Collard J, Bertrand S: Transmission of multiple resistant Salmonella concord from internationally adopted children to their adoptive families and social environment: proposition of guidelines. Eur J Clin Microbiol Infect Dis 2012, 31:491-497.

69. Maskey AP, Day JN, Phung QT, Thwaites GE, Campbell Jl, Zimmerman M, Farrar JJ, Basnyat B: Salmonella enterica serovar Paratyphi A and S. enterica serovar Typhi cause indistinguishable clinical syndromes in Kathmandu, Nepal. Clin Infect Dis 2006, 42:1247-1253.

70. Carmeli Y, Schapiro JM, Alkan M: Immigration of Ethiopians with typhoid fever to Israel: apparent lack of influence on the local population. Clin Infect Dis 1994, 19:1144-1146.

71. Worku B: Typhoid fever in an Ethiopian children's hospital: 1984-1995. Ethiop J Health Dev 2000, 14:311-315.

72. Animut A, Mekonnen Y, Shimelis D, Ephraim E: Febrile illnesses of different etiology among outpatients in four health centers in Northwestern Ethiopia. Jpn J infect Dis 2009, 62:107-110.

73. Helms M, Ethelberg S, Molbak K: International Salmonella Typhimurium DT104 infections, 1992-2001. Emerg Infect Dis 2005, 11:859-867.

74. Sibhat B, Zewde BM, Zerihun A, Muckle A, Cole L, Boerlin P, Wilkie E, Perets A, Mistry K, Gebreyes WA: Salmonella serovars and antimicrobial resistance profiles in beef cattle, slaughterhouse personnel and slaughterhouse environment in Ethiopia. Zoonoses Public Health 2011, 58:102-109.

75. Alemu S, Zewde BM: Prevalence and antimicrobial resistance profiles of Salmonella enterica serovars isolated from slaughtered cattle in Bahir Dar, Ethiopia. Trop Anim Health Prod 2012, 44:595-600.

76. Molla B, Mohammed A, Salah W: Salmonella prevalence and distribution of serotypes in apparently healthy slaughtered camels (Camelus dromedarius) in eastern Ethiopia. Trop Anim Health Prod 2004, 36:451-458.

77. Tibaijuka B, Molla B, Hildebrandt G, Kleer J, Salah W: Occurrence of Salmonellae in retail raw chicken products in Ethiopia. Berl Munch Tierarztl Wochenschr 2003, 116:55-58.

78. Molla B, Mesfin A: A survey of Salmonella contamination in chicken carcass and giblets in central Ethiopia. Rev Med Vet 2003, 154:267-270.

79. Fisk TL, Lundberg BE, Guest JL, Ray S, Barrett TJ, Holland B, Stamey K, Angulo FJ, Farley MM: Invasive infection with multidrug-resistant Salmonella enterica serotype Typhimurium definitive type 104 among HIV-infected adults. Clin Infect Dis 2005, 40:1016-1021.

80. Aseffa A, Mengistu G, Tiruneh M: Salmonella Newport: outbreak of food poisoning among college students due to contaminated undercooked eggs. Ethiop Med J 1994, 32:1-6.

81. Werner SB, Humphrey GL, Kamei I: Association between raw milk and human Salmonella Dublin infection. Br Med J 1979, 28:238-241.

doi:10.1186/1471-2334-14-88

Cite this article as: Tadesse: Prevalence of human Salmonellosis in Ethiopia: a systematic review and meta-analysis. BMC Infectious Diseases 2014 14:88

\section{Submit your next manuscript to BioMed Central and take full advantage of:}

- Convenient online submission

- Thorough peer review

- No space constraints or color figure charges

- Immediate publication on acceptance

- Inclusion in PubMed, CAS, Scopus and Google Scholar

- Research which is freely available for redistribution 